\title{
PROGRAM PIPANISASI AIR TAWAR UNTUK PENDUDUK DAERAH PESISIR PANTAI DI DESA BATU NAMPAR
}

\section{Fresh Water Pipanization Program for the Coastal Community in the Village of Batu Nampar}

\author{
Made Sutha Yadnya ${ }^{1 *}$, Sultan ${ }^{1}$, I Made Ginarsa ${ }^{1}$, I Made Ari Nrartha ${ }^{1}$, Desi Widianty ${ }^{2}$ \\ ${ }^{1}$ Jurusan Teknik Elektro Universitas Mataram, ${ }^{2}$ Jurusan Teknik Sipil, Fakultas Teknik \\ Universitas Mataram
}

Jalan Majapahit Nomor 62 Kota Mataram Provinsi NTB

*Alamat Korespondensi : msyadnya@unram.ac.id

(Tanggal Submission: 14 Agustus 2020, Tanggal Accepted: 3 September 2020)

\begin{abstract}
ABSTRAK
Pengelolaan air untuk rumah tangga khusus kebutuhan mandi, cuci, dan kakus , pada daerah yang krisis air sangat sulit karena sarana dan prasara belum ada. Salah satu program pipanisasi dilaksanakan untuk menyalurkan air bersih di Desa Batu Nampar, pelaksanaan ini bersamaan dengan KKN Tematik Universitas Mataram tahun 2019. Pipanisasi dilaksanaakan untuk penyaluran air dari tendon penanpungan ke tempat mck tersebut. Jarak untuk mengambil air (tempat pengambilan air bersama tidak lebih dari 10 meter jarak antara tiap rumah penduduk. Hasil masyarakat mendapat kemudahan dalam pengambilan air.
\end{abstract}

Kata kunci: pipanisasi, air, tendon

\section{PENDAHULUAN}

Kekeringan karena musim kemarau menyebabkan terjadinya krisis air bersih di sejumlah wilayah Nusa Tenggara Barat, khusus Pemda Lombok Timur memperdiksi diperlukan pendistribusian air bersih sekitar 17.500 liter per minggu untuk satu dusun pada tahun 2017, sementara menggunakan mobil tangki sebagai penyaluran air bersih kepada masyarakat Desa Batu Nampar Selatan, Kecamatan Kab. Lombok Timur. yang berada dipesisir pantai. Desa Batu Nampar Selatan merupakan desa yang memiliki sumber daya alam seperti hasil laut, dapat dimanfaatkan oleh masyarakat dalam kegiatan perikanan. Air bersih untuk madi cuci dan kakus
(MCK) masih sangat kekurangan, sehingga masyarakat tinggal di sekitaran desa tersebut sering mengalami penyakit diare, tipus, malaria, demam berdarah dan berbagai macam penyakit lainnya. Desa Batu Nampar Selatan merupakan desa yang termasuk kedalam wilayah yang penduduknya padat, sehingga sampah yang dihasilkan tergolong banyak dan belum terurai kondisi menumpuk dan mengeluarkan bau busuk. Faktor penyebab utamanya adalah kesadaran masyarakat yang sangat kurang dan belum adanya tempat pembuangan sampah akhir, sehingga masyarakat memutuskan membuang sampah di pinggir pantai.Keberadaan sampah di pantai dan laut dapat mengancam ekosistem kehidupan dan pencemaran lingkungan. Memasuki musim 
kemarau tahun 2018, krisis air bersih mulai dirasakan masyarakat di Desa Batu Nampar Selatan Kecamatan Jerowaru. Desa yang berada di ujung selatan Kabupaten Lotim diketahui sudah melayangkan surat ke BPBD Lotim perihal permohonan pendistribusian air bersih. Untuk menangani krisis air bersih, pihaknya sudah melakukan langkah antisipasi seperti menyiagakan personel, alat-alat dan lain sebagainya.

Air bersih setelah gempa merupakan barang sangat langka dalam bentuk kemasan, maka Pemerintah khusus Pemda NTB mengacu syarat air besih dari PP 32 tahun 2017. Penyediaan air oleh Pemda dapat dilakukan oleh penyedia secara gratis atau berbayar untuk masyarakat mengguanakan acuan sebagai dari "peraturan menteri kesehatan tentang standar baku mutu kesehatan lingkungan dan persyaratan kesehatan air untuk keperluan higiene sanitasi, kolam renang, solus per aqua, dan pemandian umum". Dengan pasal-pasal sebagai berikut: Pasal 1 Dalam Peraturan Menteri ini yang dimaksud dengan: 1.Standar Baku Mutu Kesehatan Lingkungan adalah spesifikasi teknis atau nilai yang dibakukan pada media lingkungan yang berhubungan atau berdampak langsung terhadap kesehatan masyarakat. 2.Persyaratan Kesehatan adalah kriteria dan ketentuan teknis kesehatan pada media lingkungan. 3.Air untuk Keperluan Higiene Sanitasi adalah air dengan kualitas tertentu yang digunakan untuk keperluan sehari-hari yang kualitasnya berbeda dengan kualitas air minum (Menteri Kesehatan RI, 2017).

Kekurangan air bersih di daerah terdampak gempa merupakan kendala yang harus segera diatasi. Program air siap minum untuk kondisi daerah terdampak gempa harus terpenuhi. Adapun salah satu pola untuk mengatasinya adalah : 1. Dengan memasang pompa untuk menaikan air tanah, 2. Air tanah diproses untuk mendapatkan air bersih (kalau bisa langsung dapat di minum), 3. Tanggki untuk menyimpan air yang diletakkan 3 meter dari posisi tempat pengambilan air (kran pengatur air). . Kondisi awal sebelum program air bersih daerah Lombok Timur terdapat 7 kecamatan yang masih terdampak mengalami kekeringan di tahun 2018, yakni Kecamatan Jerowaru, Keruak, Sakra Barat, Sakra, Pringgabaya, Terara dan Masbagik sebagian. Untuk musim kemarau sendiri diprediksi pada bulan November. Penanganan untuk memperkecil jumlah kecamatan terdampak kekeringan terus akan dikurangi dengan mencari sumber-sumber air untuk dilirkan ke masyarakat yang terdistibusi dengan baik.

Air bersih yang siap konsusumsi menjadi permasalahan dalam kehidupan sehari- hari warga batu nampar selatan. Dalam kehidupan seharihari, warga pada ketiga dusun yaitu dusun batu nampar tengah, batu nampar utara dan batu nampar selatan lebih banyak menggunakan air asin sebagai cara untuk menghemat air tawar, misalkan mencuci piring dan mandi. Untuk mencuci piring, biasanya warga menggunakan air asin sebagai bilasan pertama dan menggunakan air tawar sebagai bilasan terakhir. Begitupula dengan mandi, warga melakukan trik tersebut untuk lebih menghemat air. Adapun harga air pertandone di desa batu nampar selatan adalah $\mathrm{Rp} 70.000$ yang diangkut dengan mobil. Air tangki diambil dari sumur bor yang berada di Lombok Tengah dan di Desa Tutuk Kecamatan Jarowaru.

Satu rumah biasanya mendapatkan jatah membeli 1 tandone dalam waktu seminggu, tetapi ada beberapa warga yang bisa menghemat air 1 tandone dalam waktu sebulan. Selain itu, terdapat 2 sumur bor yang terletak di Dusun Temayang yang memiliki tampungan. Tampungan pertama memperoleh air dari sumur bor secara langsung, sedangkan tampungan yang kedua airnya dialirkan dari tampungan yang pertama melalui pipa.

Namun tampungan air dari sumur bor tersebut tidak mampu di alirkan ke beberapa dusun di Desa Batu Nampar Selatan karena 
terhalang oleh tanjakan dan gunung yang memisahkan beberapa dusun di desa batu nampar selatan yaitu Dusun Batu Nampar Tengah, Batu Nampar Utara Dan Batu Nampar Selatan. Sehingga penyebaran air pada tampungan sumur bor tersebut tidak dapat di alirkan ke beberapa dusun tersebut. Pernah di lakukan upaya oleh pemerintah desa setempat untuk mengalirkan air tampungan dari Temayang ke Dusun Batu Nampar Tengah, Batu Nampar Utara Dan Batu Nampar Selatan dengan cara mengeruk dan menggali tanah gunung untuk ditanami pipa aliran air, namun upaya tersebut gagal di karenakan tekanan air sangat rendah sehingga air tidak dapat di alirkan. Ketika musim hujan datang, warga biasanya menampung air yang jatuh ke genteng rumahnya dengan alat seadanya seperti bak penampung, ember dan tandone. Selama musim hujan berlangsung, warga hanya memanfaatkan air hujan untuk memenuhi kebutuhan sehari-hari dan tidak lagi membeli air.

\section{METODE KEGIATAN}

Kekurangan air bersih terus berkurang dan wilayah terdampak kekeringan telah diupayakan oleh pemerintah membangun bak penampung terhadap titik-titik yang menjadi sumber mata air, kemudian dialirkan menggunakan pipanisasi ke pemukiman penduduk. Sehingga di wilayah itu tidak lagi didropkan air bersih. Selanjutnya, yang menjadi lokasi keberadaan air bawah tanah dengan melibatkan dinas terkait dengan melakukan survei geoslistrik, maka dibangunkan sumur bor. Namun air bersih yang sampai pada titik penting belum dapat terdistribusi dengan baik maka tim pengabdian masyarakat Fakultas Teknik Universitas Mataram dengan pendanaan Mandiri berusaha melakukan pendistribusian dengan memberikan penyuluan penghematan pengunaan air bersih. Pelaksanaan pengabdian ini telah berkoordonasi dengan LPPM Universitas Mataram melalui program KKN.

Pengabdian pada masyarakat daerah pantai dan pulau pulau dilaksanakan dengan membantu masyarakat dengan komunikasi untuk dapat informasi yang sesuai dengan keputusan ekonomi agar tidak terbelilit oleh tengkulak. Salah satu daerah tersebut adalah daerah Gili Gede yang sinyal telpon GSM sangat lemah. Ini membantu agar penyampaian informasi sampai keplosokplosok (Yadnya et al, 2019). Pengabdian untuk program air bersih siap minum sudah pernah dilasanakan pengapdian di Kabupaten Lombok Utara (KLU) tepatnya di SDN 3 Teluk Nara. Progaram ini terlaksanan akibat adanya sumbangan dari Xylem berupa pompa sebesar sepuluh ribu dolar (Yadnya et al, 2020). Nilai nominal ini cukup besar yang didonasikan . Pengalaman pengabdian ini dipergunakan untuk pengabdian madiri dengan dana secukupnya. Instalasi air sekala rumahan: sekolah, tempat ibadah, kelurahan, serta rumah tangga, menjadi salah satu faktor penting yang harus diperhatikan dalam suatu areal bagunan. Membuat instalasi pompa itu, tentunya ada beberapa hal yang harus Anda pertimbangkan sebelum memilih untuk membangun instalasi pompa sendiri. Hal-hal penting tersebut diantaranya:

1. Pastikan kelancaran pasokan air tanah di lingkungan Desa Batu Nampar Selatan, kondisi tanah yang stabil dan pasokan air di musim hujan maupun di musim kemarau.

2. Pastikan kualitas air tanah di lingkungan tempat bebas dari aliran limbah, tidak berbau atau keruh.

3. Sediakan tempat untuk menaruh bak penampung atau tangki. Memang tidak harus menggunakan tangki higienis, namun untuk hemat listrik, mesin yang lebih awet dan mengantisipasi listrik disediakan disel (generator solar), maka disarankan untuk memasang tangki air. 
Jika lokasi terletak di komplek sekolah dengan luas tanah yang terbatas, ruang garasi mobil dekat pagar bisa menjadi pilihan yang baik untuk menggali sumber air. Ruang pemasangan pompa tersedia area terbuka adalah ruang terbuka, itu akan menjadi pilihan yang lebih baik lagi. Terdapat hal lain yang juga perlu pertimbangkan beberapa ketentuan dengan acuan serta aturan sebagai berikut diantaranya:

1. Jarak antara sumur dengan tangki air, jarak yang semakin dekat, maka semakin baik.

2. Jarak antara sumur dengan rencana posisi mesin jet pump, semakin dekat maka semakin bagus.

3. Ada keleluasaan untuk mengeluarkan pipa dari dalam sumur meskipun dengan posisi miring.

4. Material-material yang digunakan, salah satunya adalah pipa air.

\section{HASIL DAN PEMBAHASAN}

Persiapan dalam pelaksanaan pengabdian pada masyarakat dimulai dengan persiapan dengan mengumpulkan anggota pengabdian dan member slot waktu kapan dilakukan pengabdian untuk disesuaikan dengan KKN tematik. Yang dimaksud KKN tematik adalah Kuliah Kerja Nyata (KKN) yang orientasi program kegiatannya terfokus pada bidang keahlian tertentu sesuai dengan permasalahan yang dihadapi oleh masyarakat, diarahkan sesuai dengan kebijakan pembangunan yang diselenggarakan pemerintah wilayah tertentu (Kabupaten/Kota). Untuk Pelaksanakan KKN tematik pembimbing lapangan yaitu Sultan ST. MT sebagai fasilitator mengajak mahasiswa dan penduduk desa berpartisipasi dalam pipanisasi air tawar (dari air tadah hujan/ air sterilisasi air laut).

Adapun program yang akan kami lakukan terdiri dari program utama dan program tambahan. Program pengabdian mayarakat mandiri dipadukan dengan pelaksanaan KKN dilakukan selama 45 hari dari tanggal 23 Desember 2019 sampai 6 Februari 2020. Metode pelaksanaan disesuikan dengan jadwal KKN yaitu melalui persiapan dan pembekalan kegiatan yang akan dilakukan, pelaksanaan dari program yang telah direncanakan dan yang terakhir rencana keberlanjutan program kerja artinya masyarakat tetap dapat menjalankan kegiatan-kegiatan yang bermanfaat ini, khususnya dalam mengembangkan usaha yang telah berjalan dari program kerja KKN Tematik tidak selesai sampai disitu saja.

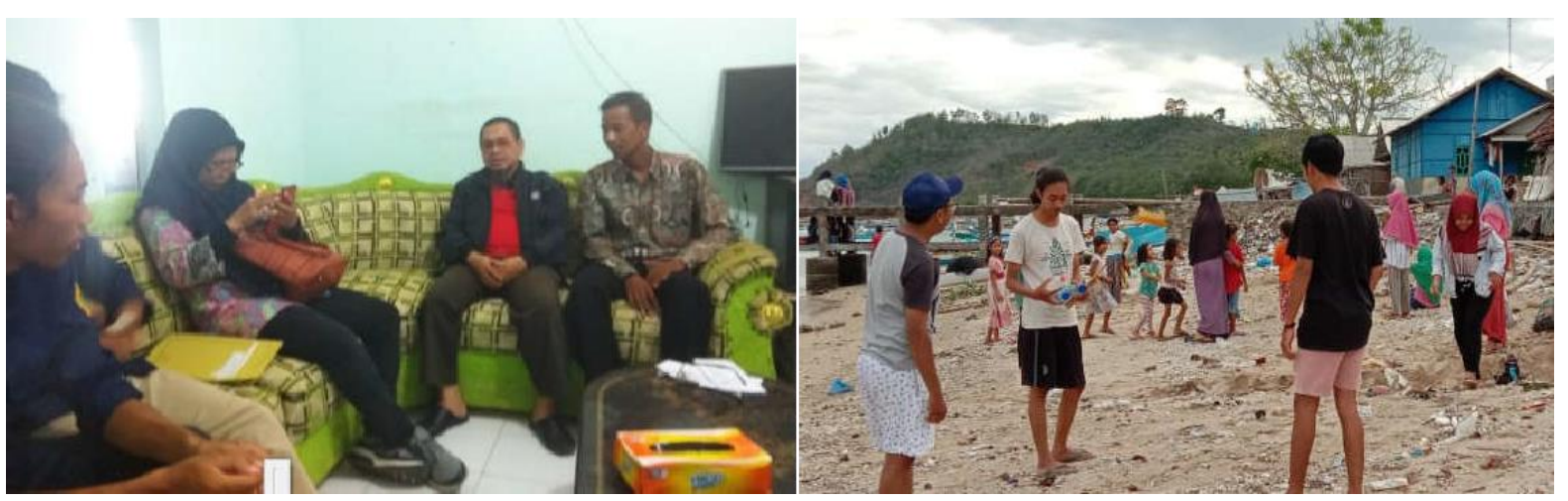

Gambar 1. Perencanaan sebelum pengabdian dengan mahasiswa KKN. daerah pesisir pantai

Pada gambar 1 digambarkan perncanaan dalam pelaksannaan pengabdian pada masyarakat. Daerah pesisir pantai kondisi seperti di
Desa Batu Nampar sangat memprihatinkan karena kesulitan air tawar. Perencanan penempatan tendon air dan pipanisasi dilakukan sesuai dengan 
situasi kondisi dilapangan. KKN tematik Universitas Mataram dengan swadaya pengumpulan dana untuk membeli tendon fiberglass untuk kebutuhan penampumgan air bersih yang akan setiap kondisi kekeringan disalurkan oleh PEMDA Lombok Timur.

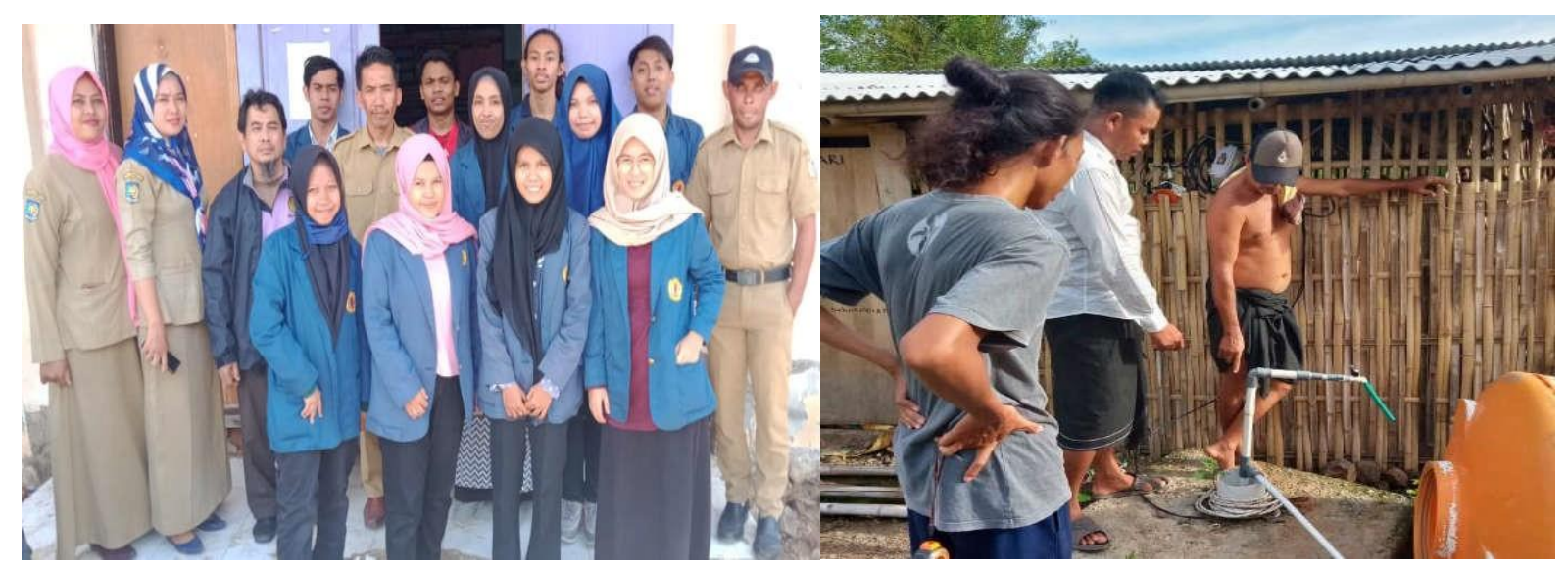

Gambar 2. Sosialisasi siswa dan penduduk Pemasangan rangka pompa

Untuk pelaksanaan dapat dilihat pada gambar 2 yaitu dengan berkunjung ke aparat desa dan silahturahmi dengan pemuka desa. Pada pemasangan pipa saluran bersama bergotong royong bersama penduduk dengan mengukur jarak sumber air dengan tangki penyimpanan air. Jarak untuk mengambil air (tempat pengambilan air bersama tidak lebih dari 10 meter jarak antara tiap rumah penduduk).

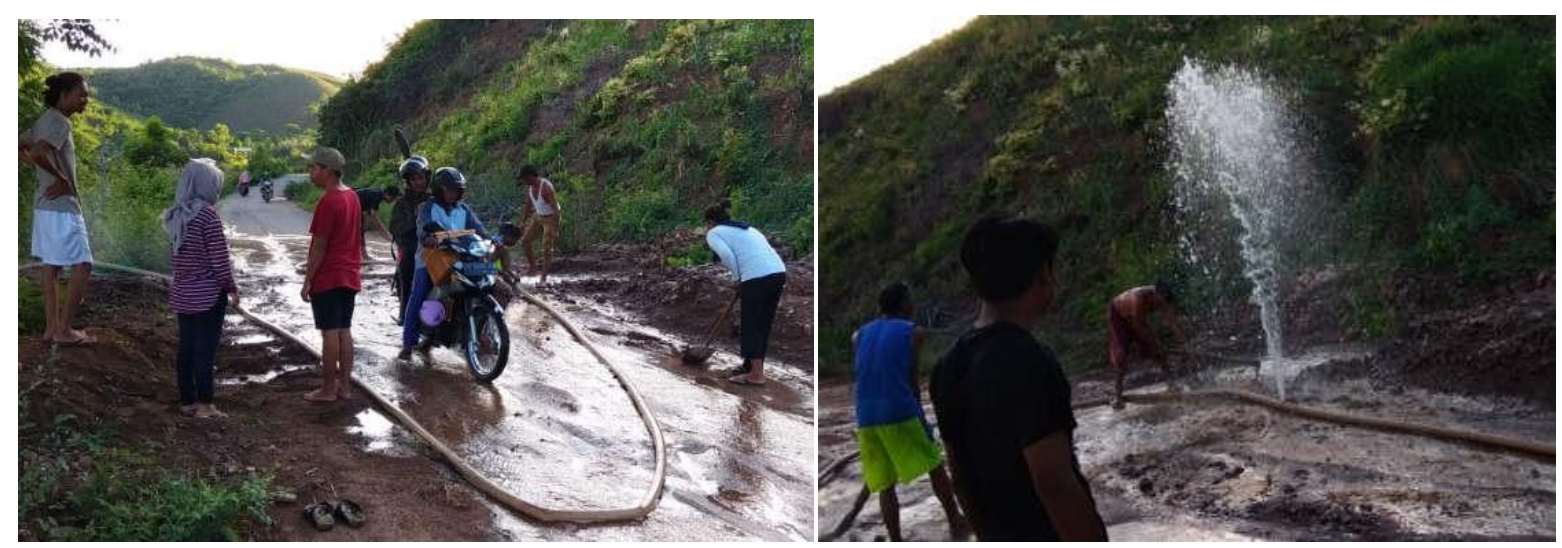

Gambar 3. Pemasangan pipa tepis tapi bocor perlu yang lebih permanen

Pada gambar 3 ternyata tidak semua yang direncanakan sesuai dengan kenyataan penyaluran air mengunakan selang berisiko. Resiko ini akihat selangnya kurang dapat menahan beban air dan akhirnya air muncrat keluar. Air yang mempunyai tekanan yang berbeda dan naik turun menyebabkan struktur pipa harus dihitung mengunakan pipa yang padat. Untuk air tadah hujan dipersiapkan beberapa bak penampungan dari campuran bata dan semen berbetuk kotak persegipanjang dengan daya tamping sekitar 100 liter sehingga air yang hujan 
turun dapat dimanfaatlan sebaik mungkin.

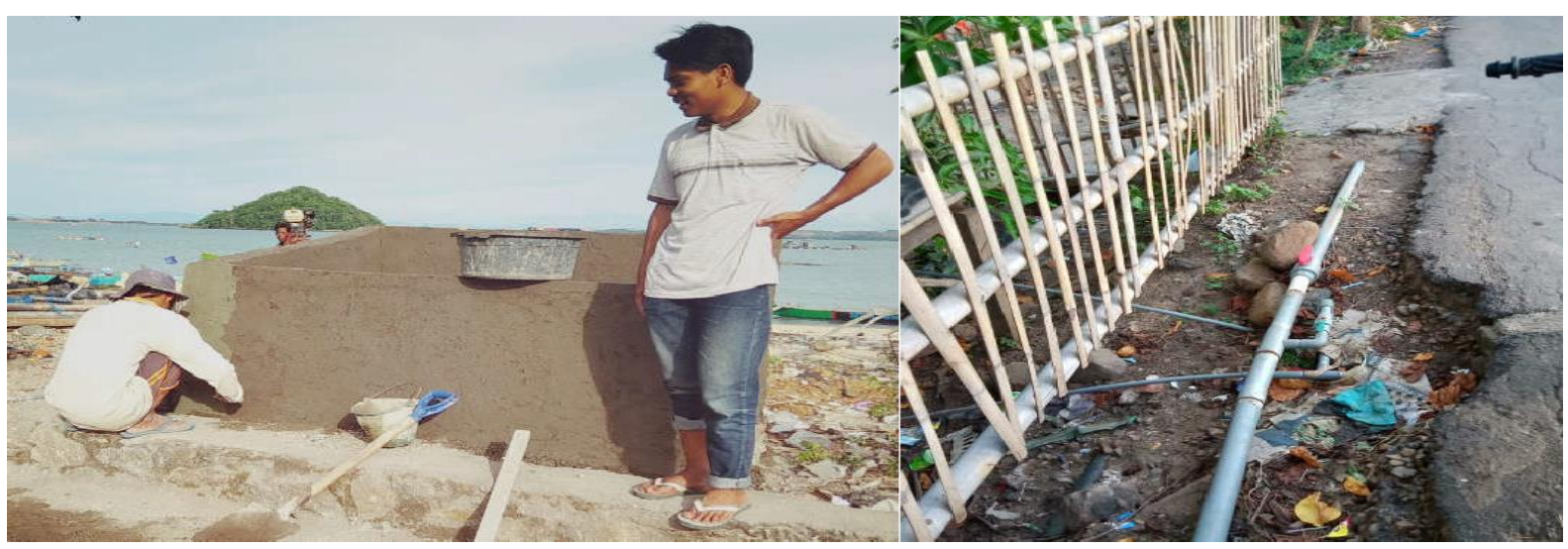

Gambar 4 Pembuatan tempat penampungan dan pipanisasi penyaluran air tawar.

Pada Gambar 4 diperlihatkan bahwa penampungan air dangan bata dan disalurkan dengan menggunakan pipa induk besar kemudian dengan pipa yang kecil pada posisi rumah yang terdekat. Air tawar yang dihasilkan baik dari air hujan atau menawarka air laut yang asin dengan sterilisasi.

\section{KESIMPULAN}

Setiap daerah mempunyai permasalan tersendiri khusus daerah pesisir pantai yang mempunyai keterbatasan air tawar perlu adanya kepedulian dunia pendidikan dan usaha serta kalangan cendekiawan dapat bersatu untuk membatu masyarakat sebagai kepedulian dan penerapan hasil penelitian yang telah dilakukan. serta penduduk sekitarnya dapat memanfaatkan air untuk diminum secara langsung atau digunakan untuk memasak dan kebutuhan sehari-hari tanpa mengenal musim kemarau(kering) atau hujan. Usaha yang dilakukan dari KKN tematik ini adalah pemicu untuk dilakukan kegiatan ini agar tetap berlangsung. Syukur untuk sementara penyaluran air melaui pipa dapat mempersingkat waktu, sehingga air sudah dapat diambil tanpa perlu lama akibat dari penampungan air dengan pipanisasi jauh lebih dekat.

\section{UCAPAN TERIMA KASIH}

Terima kasih diucapkan kepada Peserta KKN Tematik di Desa Batu Nampar yang sudah bersinergi dalam melaksanakan pengabdian ini, aparat desa, penduduk desa, serta semua yang tidak disebutkan satu persatu dalam membantu dan menfasilitasi peyelesaian makalah ini. Pembiayaan untuk publikasi ini sepenuhnya menggunakan dana mandiri yang dikumpukan dari setoran setiap anggota pengabdian pada masyarakat. Semoga makalah ini dapat inspirassi dari kegiatan-kegiatan selanjutnya.

\section{DAFTAR PUSTAKA}

BPBD , (2018) , "Laporan CNN Indonesia Selasa, 07/08/2018 18:59 WIB" Berita langsung diakses tanggal 24 April 2019

Menteri Kesehatan RI. 2017. PERATURAN MENTERI

KESEHATAN REPUBLIK INDONESIA NOMOR 32 TAHUN 2017, diakses tanggal 26 April 2019.

Sultan dalam Laporan KKN Tematik, (2020)"

Ooptimalisasi Penyediaan Air Minum

Dan Sanitasi Lingkungan Melalui

Partisipasi Masysrakat Di Desa Batu 
Nampar Selatan Kecamatan Jerowaru Kabupaten Lombok Timur " Universitas Mataram 13 Februari 2020.

Yadnya M.S, CMO Movianto, C Rahmadani, INW Satiawan, IBF Citarsa (2019)., "Pemasanagan Perangkat Penguat Daya GSM di Pulau Gili Gede Kabupaten Lombok Barat Provensi Nusa Tenggara Barat" . Jurnal Abdi Insani LPPM Universitas Mataram.
Volume 6 (2) halaman 241-250.

Yadnya M.S . Tahmid A, Zainuddin A. Zubaidah T. Kanata B. Paniran (2020), " Program Air Siap Minum Untuk Siswa dan Penduduk Terdampak Gempa di Sekolah Dasar Nengeri 3 Malaka Teluk Nara Pemenang, Kabupaten Lombok Utara" . Jurnal Gema Ngabdi LPPM Universitas Mataram. DOI : https://doi.org/10.29303/jgn.v2i1.71. 